\title{
O PAPEL CONSTRUTIVO DAS INCUBADORAS NO ALINHAMENTO ESTRATÉGICO E MERCADOLÓGICO DAS EMPRESAS INCUBADAS E GRADUADAS
}

\author{
Gustavo Abib - PPGADM/UFPR ${ }^{1}$ \\ Paulo Hayashi Junior - UNICAMP ${ }^{2}$ \\ Marcia May Gomel - PPGADM/UFPR ${ }^{3}$ \\ Marcos Wagner da Fonseca - PPGADM/UFPR ${ }^{4}$
}

Resumo: O presente estudo tem como objetivo principal analisar e descrever as relações estratégicas de produção e de mercado de empresas que ainda estão em processo de incubação e as já graduadas, bem como a adequação das incubadoras como instrumento de alavancagem de desenvolvimento empresarial. A metodologia utilizada é a de estudo multicasos, realizada com 36 empresas localizadas em quatro incubadoras no Estado do Paraná. Foram entrevistados os empreendedores de empresas incubadas e graduadas, como também os gestores responsáveis pelas incubadoras. Os principais resultados encontrados são: a) foco estritamente no desenvolvimento de novos produtos pelas empresas incubadas; b) falta de alinhamento com o mercado em geral, resultando num retorno de muitas empresas para uma segunda reincubação; c) ineficiência na aplicação dos fomentos recebidos. Pode observar-se que parte deste problema está refletido nas deficiências das políticas de admissão e na falta de mecanismos que auxiliem na construção de comprometimento entre as empresas e os recursos de fundos perdidos, assim como as graduadas e as incubadoras industriais.

Palavras-chaves: Empreendedorismo; Incubadoras Tecnológicas; Alinhamento Estratégico.

\section{THE CONSTRUCTIVE ROLE OF BUSINESS INCUBATORS ON STRATEGIC AND MARKETING ALIGNMENT OF INCUBATED AND GRADUATE FIRMS}

\begin{abstract}
This study aims to describe and analyze the initial production and market strategic relationship of small businesses that are in the process of incubation and the ones that recently graduated from business incubators. Also intend to reveal the adequacy of the incubators as a tool to leverage business development. The methodology used is a multiple cases of 36 companies located in four incubators in the state of Parana. Entrepreneurs from the businesses were interviewed as well as

\footnotetext{
${ }^{1}$ Email: gustavo.abib@gmail.com. Endereço: Rua Pref. Lothário Meissner 632, 2 andar CEP: 80210-170 - Curitiba/PR.

${ }^{2}$ E.mail: paulo.hayashi@hotmail.com

${ }^{3}$ E,mail: marciamay@gmail.com

${ }^{4}$ E.mail: marcos.w.fonseca@gmail.com
}

ABIB, G. et al; O papel construtivo das incubadoras no alinhamento estratégico e mercadológico das empresas incubadas e graduadas. Revista de Empreendedorismo e Gestão de Pequenas Empresas, v.1, n.2, 2012. 
the managers responsible for the incubators. The main findings are: a) focus strictly on developing new products by companies incubated; b) difficulties of alignment with the market, resulting in a return of many companies for a second incubation process; c) inefficiency in the application of fomentations received. It may be noted that part of this problem is reflected in the deficiencies in admission policies and the lack of mechanisms that assist in building engagement between companies and resources funds lost as well as graduate and industrial incubators.

Keywords: Entrepreneurship; Technological Incubators; Strategic Alignment.

\section{Introdução}

Antes de tudo, vale dizer que a necessidade de adaptação ambiental frente a um ambiente hiper competitivo (GRANT, 1991; LEWIN; VOLBERTA, 2006; VOLBERTA, 1998) propicia o desenvolvimento de novas formas organizacionais (SNOW; MILES, 1983) como as networks corporativas e outras associações como as incubadoras industriais. Também favorece a aproximação de abordagens estratégicas bastante conhecidas, como as de Miles e Snow (1978) e a de Porter (1980), por exemplo, em torno do alinhamento estratégico.

Surgida desta necessidade e fortemente calcada em uma sociedade do conhecimento, as incubadoras são organizações impares que têm como objetivo preparar novas empresas - incubadas - na elaboração de seus produtos e relacionamentos com o mercado por meio da criação, transferência de conhecimento e tecnologia entre as universidades e as incubadas. Esta geração e transferência de conhecimento devem extrapolar os primeiros meses de vida, a ponto de preparar as incubadas para competir e sobreviver em um mercado altamente competitivo e globalizado.

Segundo definição proposta por uma das principais entidades de fomento de incubadoras no Brasil, a Associação Nacional de Entidades Promotoras de Empreendimentos Inovadores (ANPROTEC) - uma incubadora tem como princípio não apenas à proteção de novas empresas, mas também o seu desenvolvimento para a criação de outras novas. Há um aumento do número de empresas incubadas. Como exemplo desta afirmativa, no ano de 2009 chegam à marca de 400 
incubadoras no país (três vezes o número de incubadoras do ano de 2000) (ANPROTEC, 2009).

Revisando a literatura especializada, o olhar dos pesquisadores tem se voltado ao papel das incubadoras na formação de iniciativas empreendedoras auto gerenciáveis. Os trabalhos de Calbino (2010), Calbino e Paula (2010), Cohen, Louzada, Lucena e Melo (2009), Engelman e Fracasso (2010), Gallon, Lyrio e Ensslin (2008), Melo e Cohen (2009), Nunes e Antunes (2010), Oliveira, Oliveira e Pereira (2010), Ramos e Alperstedt (2011), Santos e Alves (2009), Silva, Gomes e Correia (2009), Vedovello e Figueiredo (2005), demonstram o aumento do interesse pela questão. O apoio dos órgãos de fomento a essas iniciativas também corroboram para a constatação de crescimento das incubadoras.

A respeito da estratégia, Richers (1981) enuncia que é a escolha de um caminho de ação de uma empresa para alcançar o sucesso. Para Porter (1980), posicionar adequadamente a empresa com o seu meio ambiente é a essência da formulação de estratégias competitivas. Já Ansoff (1965) procura tratar a estratégia como a área relativa da organização que busca o ajustamento deliberado para com o seu ambiente. Ansoff e McDonnell (1993) consideram que a relação com o ambiente é apenas parte do conjunto de regras de decisão que forma a estratégia. Já para Chaffee (apud MINTZBERG; AHLSTRAND; LAMPEL, 2000, p. 21), "uma premissa básica para se pensar a respeito de estratégia diz respeito à impossibilidade de separar organização de seu ambiente [...] a organização usa a estratégia para lidar com as mudanças nos ambientes." Através dos autores acima, percebe-se a real importância do alinhamento da empresa com o mercado.

Entretanto, será que o papel e a abordagem das incubadoras são suficientes para propiciar tal desenvolvimento para as empresas incubadas? E para aquelas "graduadas" que já passaram pelo processo de incubação e estão "fora" das incubadoras, será que tiveram uma formação sólida?

Tendo em mente tais preocupações, o presente trabalho utiliza tanto a abordagem estratégica da Visão Baseada em Recursos (VBR), quanto o empreendedorismo como meio integrador e holístico para posicionar a empresa 
frente a um ambiente cooperativo, competitivo, dinâmico. O objetivo principal é analisar e descrever as relações estratégicas de produção e de mercado de empresas que estão ainda em processo de incubação e as já graduadas, bem como a adequação das incubadoras como instrumentos de alavancagem de desenvolvimento empresarial apto a competir em mercados altamente competitivos.

Este artigo está estruturado em cinco partes: a introdução, seguida pelo arcabouço teórico utilizado, a metodologia adotada, a discussão dos resultados e por fim, as considerações finais. Na última parte ainda são apontadas futuras possibilidades de pesquisa.

\section{Empreendedorismo}

No Brasil, segundo Dornelas (2001), o empreendedorismo ganhou força a partir da década de 90 com a abertura da economia e a criação de entidades como o Sebrae e o Softex, ambos voltados para o fomento empreendedor. Apesar de o Brasil despontar como o país que contém o maior número de empreendedores entre 18-64 anos das economias direcionadas à eficiência segundo o relatório de 2010 do Global Entrepreunership Monitor (GEM), é também o que possui a menor orientação externa. Questiona-se, desta forma, se o ajustamento entre a empresa e o mercado são suficientes e adequados para a própria sobrevivência. Essa questão é reforçada por Hisrich e Peters (2009), apontando que não basta apenas possuir recursos financeiros e estruturais bem organizados, mas é necessário também certo ajustamento entre as necessidades do mercado e o negócio. Ainda segundo os autores, isso pode ser alcançado com investimento em novos produtos, criatividade e espírito empreendedor.

De acordo com Filion (2004, p. 65), o empreendedorismo é definido como sendo um "processo pelo qual se faz algo novo (algo criativo) e algo diferente (algo inovador) com a finalidade de gerar riqueza para indivíduos e agregar valor para a sociedade". Todavia, ainda que o tema tenha sido explorado por diferentes 
perspectivas, parece haver pouca concordância sobre o assunto, o que demonstra 0 processo de amadurecimento e a sua consolidação enquanto campo do saber.

Os estudos sobre empreendedorismo, conforme ressaltam Ferreira, Gimenez e Ramos (2005), são complexos, multifacetados, multiníveis e dinâmicos. Deste modo, com intuito de diferenciar termos que costumam transitar sem a devida cautela, torna-se necessário explorar os seguintes conceitos: empresário e empreendedor, e ainda, empreendedor e intraempreendedor.

O empreendedor é aquele que "imagina, desenvolve e realiza visões" (FILION, 2004, p. 65). Já o empresário é o dono do negócio, sendo que não precisa ser necessariamente empreendedor. Além disso, nem todo empreendedor precisa ser empresário, pode ser funcionário de uma organização. Nessa linha, há uma definição conceitual do intraempreendedor. Por outro lado, buscando nos resultados do trabalho de compreensão fenomenológica realizados por Boava, Macedo e Lopes (2006), percebe-se que o tema empreendedorismo apresentou quatro unidades de sentido: desenvolvimento de habilidades, visão de futuro, saber fazer e potencialidade.

Diversos trabalhos de orientações diferentes têm contribuído de maneira parcial para a situação, como nos estudos de aprimoramento de habilidades desenvolvidos por Dornelas (2004). Outro ponto é fazer aquilo que gosta (DOLABELA, 2008; HOELTGEBAUM, 2004). Ou então, o empreendedorismo como uma promessa (de emancipação) (BOAVA; MACEDO, 2011). Já Filion (2004) associa o empreendedorismo com a habilidade de interligar a capacidade operacional com a visão de futuro. Em uma linha mais emergente e com estudos quantitativos, Gimenez vem desenvolvendo trabalhos concomitantes ao potencial empreendedor, principalmente calcado na questão da Liderança Criativa e do Carland Entrepreneurship Index (CEI).

Ainda que os estudos sobre empreendedorismo venham se difundindo, 0 campo para pesquisas é vasto. No presente estudo, pesquisa-se a contribuição das incubadoras para a sustentabilidade do empreendedorismo, ou seja, a estruturação e preparação das empresas para o mercado e o ato contínuo de realinhamento. 


\section{Incubadoras}

De acordo com Martins et al. (2005), o termo incubadora conota um ambiente controlado, como uma estufa pré-natal que serve à proteção da vida de novas empresas. Sua utilidade não é apenas proteção, mas sim a de incentivos à criação e ao desenvolvimento. De acordo com a Associação Nacional de Entidades Promotoras de Empreendimentos Inovadores (ANPROTEC, 2009), uma incubadora é:

É um local especialmente criado para abrigar empresas oferecendo uma estrutura configurada para estimular, agilizar, ou favorecer a transferência de resultados de pesquisa para atividades produtivas. Para isso a Incubadora oferece apoio gerencial e técnico (serviços de recepção e secretaria, salas de reunião, Internet, telefone, etc.) e uma gama de serviços que propiciam excelentes oportunidades de negócios e parcerias, para que você desenvolva seu projeto/ empresa.

Um dos valores destacados pela entidade como vantagens de uma empresa incubada é o potencial de sucesso, devido não apenas à proteção, mas também pela possibilidade de geração de novas ideias e oportunidades ao contato e troca de informações e experiências com outras empresas incubadas. Além dos fatores já apresentados, inúmeras são as fontes de financiamento para as empresas incubadas, inclusive com recursos não reembolsáveis (subvenção econômica) e a transferências de tecnologia na relação universidade-empresa.

Lichtenstein e Lyons (1996) identificam as incubadoras como um importante catalisador do processo empreendedor, essencial para a consolidação das empresas no mercado. Similarmente, Smilor, Gibson e Dietrich (1990) relatam que a incubadora busca unir talento, tecnologia, capital e experiência das pessoas, além de acelerar o desenvolvimento de novas empresas. De acordo com Lalkaka (1996, p. 271), os principais fatores que determinam o sucesso de uma incubadora são: 
- A seleção de bons parceiros na comunidade;

- Estabelecimento de metas realistas;

- Equipe gerencial capacitada e dinâmica;

- Instalações que estimulam a criatividade e a interação entre as empresas incubadas.

Com o objetivo de apresentar um conciso panorama das incubadoras no Brasil, a figura 1, retirada do último estudo de panorama da Anprotec, aponta que a distribuição geográfica das incubadoras segue a concentração das empresas e dos polos de tecnologia no Brasil. Ou seja, há uma grande concentração das incubadoras nas regiões Sul e Sudeste.

Figura 1 - Distribuição Geográfica das Incubadoras.

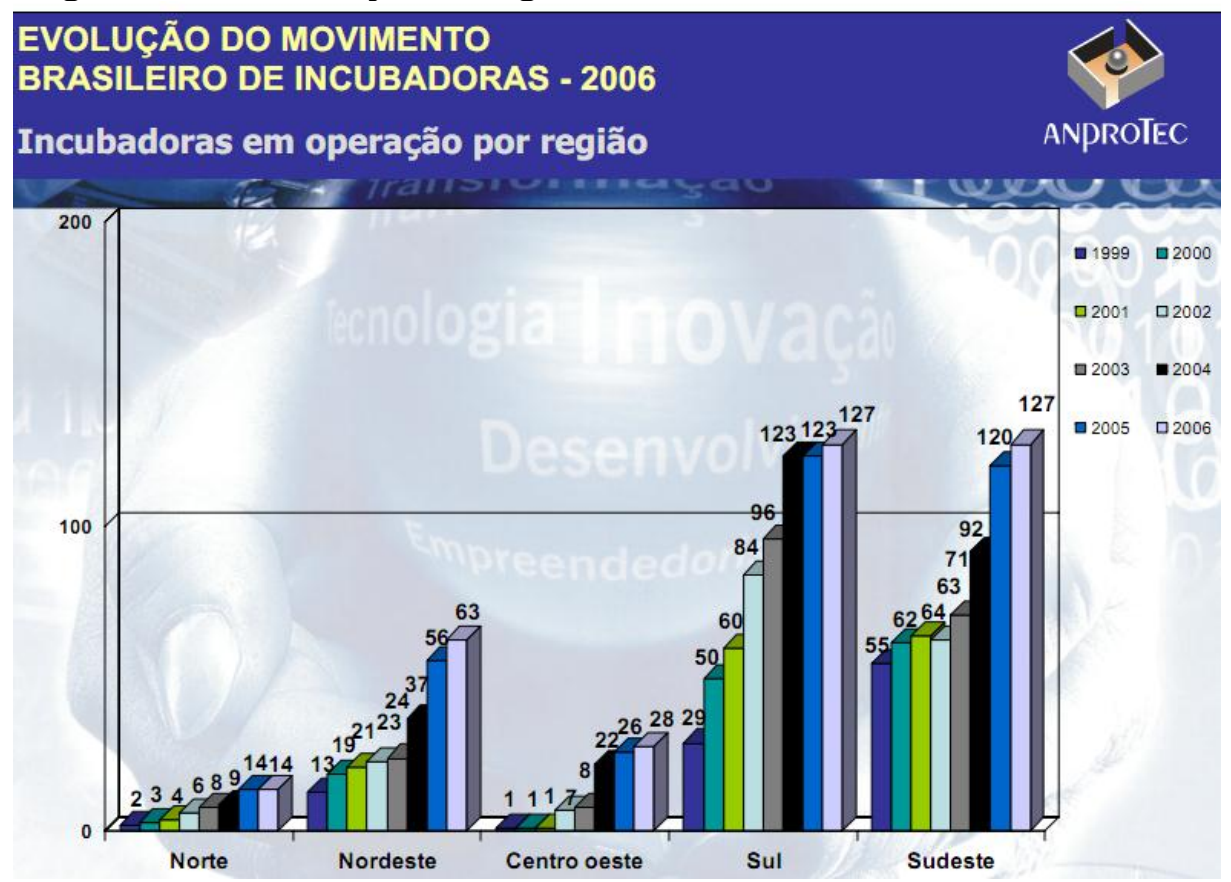

Fonte: Associação Nacional de Entidades Promotoras de Empreendimentos Inovadores. (2006). Panorama 2006. Recuperado em 1 julho, 2011. Disponível em: <http://www.anprotec.org.br/ArquivosDin/Graficos_Evolucao_2006_Locus_pdf_59.pdf>.

Constata-se ainda, que as incubadoras convergem importantes elementos para as empresa que ali se abrigam, tais como: potencialização do 
empreendedorismo; inovação, capital e transferência de tecnologia e gestão. Mas mesmo com esse conjunto de benefícios que diferenciam estas empresas de outras não incubadas, inúmeros são as dificuldades de posicionamento mercadológico de empresas incubadas e graduadas.

\section{Estratégia e Visão Baseada em Recursos}

Importante observar que as abordagens contemporâneas adotam a estratégia não com o sentido de disciplina, função, ou kit de ferramentas, mas como agenda de "uma série de questões fundamentais e problemas que se relacionam as organizações e seus sucessos" (JENKINS; AMBROSINI; COLLIER, 2002, p. 1). De modo complementar, para Snow e Miles (1983) a estratégia foca tanto o ambiente interno quanto o externo e busca a adequação entre ambos. Para Gimenez, Pelisson, Krüger e Hayashi (1999), a estratégia é um fenômeno complexo e dificilmente tem apenas um único fator como responsável, podendo ser vista como um padrão de decisões que levam a comprometimentos de ações, recursos, capacidades e competências organizacionais. Ou seja, ao longo da trajetória de uma empresa, seus administradores tomam decisões sobre investimentos e alocação de recursos, bem como acerca das atividades e competências a serem desenvolvidas por seus colaboradores, o que gera certo comportamento e desempenho da empresa.

A visão baseada em recursos (VBR) é uma das abordagens que vem ganhando espaço dentro da literatura estratégica e tenta explicar diferenças de desempenho das organizações por meio de seus recursos e competências, não mais pela estrutura da indústria (BARNEY; HESTERLY, 1996). A VBR busca nos recursos das organizações a fonte para as vantagens competitivas sustentadas e é expressa da seguinte maneira, conforme Montgomery e Wernerfelt (1991, p. 955): "de uma perspectiva de recursos, empresas lucram mais e geralmente tem participações de mercado mais altas, se eles têm 'recursos melhores"'. Por melhores recursos, os autores se referem àqueles que possibilitam a empresa obter vantagem ABIB, G. et al; O papel construtivo das incubadoras no alinhamento estratégico e mercadológico das empresas incubadas e graduadas. Revista de Empreendedorismo e 
competitiva e que são difićlimos de serem replicados pelos competidores com custos iguais, e que a tarefa da administração reside no aproveitamento de tais recursos.

Por recursos entende-se os ativos tangíveis e intangíveis que são vinculados de forma semipermanente à empresa (WERNERFELT, 1984). Schulze (1994) define de maneira mais pontual, como sendo os elementos que participam do processo produtivo, tais como: máquinas e equipamentos, habilidades dos trabalhadores, marcas e patentes, etc. Já Barney (1997) considera como recursos todos os ativos, as competências, o processo organizacional, os atributos e as informações da empresa, o conhecimento, enfim uma ampla gama de ativos que pertencem à empresa.

Segundo Galunic e Rodan (1998), as competências são recursos baseados em conhecimento que existe nos diversos níveis hierárquicos. Competências, ao contrário dos recursos, envolvem padrões complexos de coordenação e cooperação entre pessoas e entre pessoas e recursos (GRANT, 1991), e influenciam na produtividade dos recursos (SCHULZE, 1994). Já Day (1994, p. 38) define competências como sendo "fardos complexos de habilidades e aprendizagem coletiva, exercitados por meio do processo organizacional e que assegura coordenação superior das atividades funcionais". Além disso, para o autor, a diferença entre competências e ativos patrimoniais reside na possibilidade de atribuir valores monetários a estes últimos. Ademais, competências que possibilitam a empresa sustentar com distinção certas linhas de negócio são chamadas de essenciais. Wright, Kroll e Parnell (2000) comentam que na criação de valor para os clientes, as empresas buscam calcar suas atividades em suas competências essenciais, deixando para outras empresas as atividades e processos que elas não conseguem ser excelentes, ou que não fazem parte do núcleo central de negócios.

A própria acumulação de conhecimentos sobre a VBR também se mostra importante e a partir de 2000, com o artigo de Bowman e Ambrosini (2000) e de Priem (2007), bem como os artigos de cocriação de valor, principalmente de Prahalad e Ramaswamy (2000, 2002, 2004), a VBR parece adentrar em uma nova 
era. Ou seja, está mais focada na questão do que é valor e da importância da percepção e participação do consumidor sobre este valor. Isso vem de encontro às críticas de Kraaijenbrink, Spender e Groen (2010), para quem a VBR precisa se desvencilhar do foco estreito da economia neoclássica e, principalmente, buscar um viés mais dinâmico e comprometido com o mercado.

A próxima seção abordará o arcabouço metodológico utilizado.

\section{Método de Pesquisa}

A presente pesquisa caracteriza-se por ser um estudo multicasos com caráter descritivo e exploratório (YIN, 2001), envolvendo quatro incubadoras do Estado do Paraná. Entrevistou-se 36 dirigentes de empresas incubadas e graduadas. As incubadoras e as empresas foram intencionalmente selecionadas através dos critérios propostos por Yin (2001) para a seleção de casos. Foram critérios de seleção: homogeneidade funcional, sendo todas de base tecnológicas; a região de localização; tamanho; representatividade; parcerias estratégicas com universidades e instituições de fomento.

A coleta de dados é caracterizada como qualitativa (CRESWELL, 2003), por ser mais adequada para pesquisas que procuram descrever a complexidade de determinado fenômeno (RICHARDSON, 1999). Entrevistou-se ainda, os gestores estratégicos e táticos das empresas e os gerentes das incubadoras. Outra parte relevante dos dados foi obtida por análise documental (documentos de incubação e notícias sobre as empresa na mídia).

Para tanto, a pesquisa utilizou como fontes de evidências, entrevistas baseadas em questionários semiestruturados, documentos e observação não participante. As entrevistas semiestruturadas são a principal fonte de dados deste trabalho. Foram realizadas 36 entrevistas com os gestores das empresas que também preencheram um questionário fechado e mais 4 entrevistas com os gestores das incubadoras, perfazendo um total de 40 entrevistas. Cada entrevista teve duração média de uma hora, sendo a maior com duração de uma hora e ABIB, G. et al; O papel construtivo das incubadoras no alinhamento estratégico e mercadológico das empresas incubadas e graduadas. Revista de Empreendedorismo e 
quarenta e sete minutos. A pesquisa documental ocorreu a partir de documentos fornecidos pelas incubadoras que retratavam as políticas de ingresso das empresas interessadas.

Após a realização das entrevistas, os dados coletados foram categorizados por meio da técnica de análise de conteúdo, tendo por objetivo delinear com clareza as categorias de análise que se pretendeu investigar (FREITAS; JANISSEK, 2000). Seguindo a metodologia sugerida por Bardin (1994), a análise de conteúdo foi dividida em três fases: a pré-análise, exploração do material e tratamento dos resultados.

Nesta pesquisa a pré-análise consistiu na organização do material bibliográfico, bem como na busca e organização de materiais das incubadoras e das empresas que seriam estudadas. Isto teve como objetivo entender como cada uma das categorias e seu conjunto se destacam nas práticas das empresas estudadas.

Após a realização das entrevistas, houve a transcrição para análise das categorias criadas. A definição das categorias seguiu o modelo fechado (LAVILLE; DIONNE, 1999), que consiste em o pesquisador decidir a priori as categorias apoiadas em um ponto de vista teórico que submete, frequentemente, à prova da realidade. As categorias foram criadas a partir dos principais fatores de sucesso e barreiras enfrentadas pelas empresas na colocação dos seus produtos no mercado. $\mathrm{Na}$ análise dos fatores de sucesso das empresas, foram utilizadas as categorias propostas pela visão baseada em recursos (BARNEY, 1997).

\section{Validade e Confiabilidade da Pesquisa}

Para incrementar a validade e a confiabilidade da pesquisa, alguns procedimentos foram adotados buscando permitir que outros pesquisadores possam chegar a considerações semelhantes. De acordo com Yin (2001), a confiabilidade pode ser obtida através da validade externa e a de construto. A validade do protocolo de estudo de caso utilizado nesta pesquisa foi obtida através da validade de face e de conteúdo.

ABIB, G. et al; O papel construtivo das incubadoras no alinhamento estratégico e mercadológico das empresas incubadas e graduadas. Revista de Empreendedorismo e 
A validade do construto foi buscada com a utilização de várias fontes de evidências e após a análise dos dados, foram remetidos aos entrevistados para sua análise. Em um dos casos, o relatório retornou com informações adicionais. Em relação à validade externa, enseja que este possa ser replicado, buscou-se entrevistar os fundadores da empresa por conhecerem todos os fatos relacionados à sua empresa.

O protocolo de pesquisa caracteriza-se como imprescindível para o incremento da confiabilidade, especialmente em múltiplos casos, e contém o instrumento, os procedimentos, as questões e as regras de utilização do mesmo. Após a realização das entrevistas, um banco de dados foi criado para organizar as evidências e ideias.

\section{Ambiente de Estudo}

Segundo dados da Anprotec, em 2006 o Brasil possuía 377 (trezentos e setenta e sete) incubadoras ou parques tecnológicos, sendo 127 (cento e vinte e sete) concentrados na região Sul, sendo que 24 (vinte e quatro) no Estado do Paraná. Ainda de acordo com a Anprotec (2006), estas entidades abrigam juntas 2.327 (dois mil, trezentos e vinte e sete) empresas incubadas e já graduaram 1.678 (um mil, seiscentos setenta e oito) empresas. A maioria destas incubadoras caracteriza-se como entidades privada sem fins lucrativos (66\%), seguidas de naturezas jurídicas públicas federais e municipais (11\% e 11\%) e por fim, $12 \%$ se constituem de outros tipos. O foco de atuação das incubadoras está concentrado em tecnologia, correspondendo a $40 \%$ das incubadoras, $23 \%$ mistas e $18 \%$ tradicionais, sendo $19 \%$ os outros.

As quatro incubadoras que constituíram a pesquisa estão localizadas na região de Curitiba, sendo todas ligadas ao ramo de tecnologia e associadas à Rede Paranaense de Incubadoras e Parques Tecnológicos (Reparte). A tabela 1 caracteriza a incubadora, a instituição de vínculo e também a localidade. 
Tabela 1 - Relação de Incubadoras Pesquisadas.

\begin{tabular}{|c|c|c|c|}
\hline & NOME & ENTIDADE DE FILIAÇÃO & REGIÃO \\
\hline 1 & $\begin{array}{l}\text { Núcleo de Empreendedorismo e } \\
\text { Projetos Multidisciplinares }\end{array}$ & Universidade Federal do Paraná & Curitiba \\
\hline 2 & Hotel Tecnológico & $\begin{array}{l}\text { Universidade Tecnológica Federal do } \\
\text { Paraná }\end{array}$ & Curitiba \\
\hline & $\begin{array}{l}\text { Incubadora do Instituto de } \\
\text { Engenharia do Paraná. }\end{array}$ & Instituto de Engenharia do Paraná & Curitiba \\
\hline & $\begin{array}{l}\text { Hotel Tecnológico // Incubadora } \\
\text { Tecnológica de Ponta Grossa }\end{array}$ & $\begin{array}{l}\text { Universidade Tecnológica Federal do } \\
\text { Paraná e UEPG }\end{array}$ & $\begin{array}{l}\text { Ponta } \\
\text { Grossa }\end{array}$ \\
\hline
\end{tabular}

Fonte: Os autores, 2012.

Entre as 36 empresas pesquisadas, 4 estavam em pré-incubação, 20 incubadas, 03 reincubadas e 9 graduadas. O estágio de pré-incubação é quando a empresa ainda está desenvolvendo a concepção do seu produto. As empresas incubadas eram as que já estavam desenvolvendo seus produtos e ainda não completaram o prazo de dois anos dentro da incubadora. Três empresas obtiveram a graduação, porém não conseguiram permanecer no mercado, retornando à incubadora. Por fim, foram analisadas 9 empresas que saíram das incubadoras e estavam atuando no mercado.

\section{Análise dos Resultados}

A análise dos resultados alcançados, para melhor sistematização, foi dividida em três partes: análise entre as empresas graduadas e incubadas, a política de admissão das incubadoras e o comprometimento dos participantes.

\section{Empresas Graduadas e Incubadas}

Neste ponto, é interessante relembrar que as empresas graduadas são aquelas que se desligaram da incubadora para alçar funcionamento autônomo. Foi unânime entre as empresas pesquisadas, o reconhecimento da importância da 
incubadora para o início do negócio. Apesar de se tratar somente de empresas de tecnologia que envolvia desde a produção de software (baixo investimento) até projetos mais complexos, com a utilização de tecnologia de proteção elétrica para redes de telefonia (alto investimento), todas as empresas reconheceram a importância da incubadora em estágios de pré-incubação até a concepção final dos produtos.

Um fato que também deve ser mencionado é a ligação de todas as incubadoras a instituições de ensino superior. Algumas estão relacionadas diretamente a cursos específicos, como as engenharias e ciências da computação. Este fato remete as empresas a contatos diretos com professores e pesquisadores destas instituições.

Segundo relato das empresas incubadas, muitos projetos são disponibilizados pelas incubadoras para as empresas e nestes projetos, muitos profissionais são disponibilizados para as auxiliarem. A maioria destes projetos está relacionada com a parte de criação e desenvolvimento do produto. Quando se fala em produção, entende-se desde a concepção, desenvolvimento do protótipo até 0 desenvolvimento do modelo final. Durante estas etapas, as empresas incubadas recebem auxílio praticamente constante das instituições de ensino a que estão filiadas e de outros profissionais custeados com os recursos da incubadora ou fontes de fomento.

A maioria das empresas incubadas afirmou que a ideia para a criação do produto surgiu do próprio fundador e, em outros casos, surgiu de algum projeto disponível na faculdade que foi posteriormente desenvolvido por um grupo de empreendedores. Algumas ainda iniciaram o desenvolvimento de um produto e modificou totalmente o foco depois que um possível cliente solicitou algo diferente. É comum as empresas mudarem seus produtos/serviços na busca de recursos de curto prazo para manutenção do negócio.

Diante destes relatos, constatou-se uma intensa concentração dos investimentos na parte produtiva das empresas incubadas. Esta concentração se mantém desde o período inicial da incubação até a data da graduação da empresa. 
A concentração de esforços e recursos na parte produtiva aliada a ideia empreendedora inicial desenvolve, em alguns casos, bons produtos e em muitos outros, acaba desenvolvendo produtos sem alinhamento mercadológico.

Isto pode ser observado quando se analisam as empresas incubadas que estão com seus produtos prontos para o mercado e também com exemplos das empresas graduadas. As empresas incubadas que concluíram seus produtos tiveram dificuldades para se inserir no mercado devido a falta de alinhamento entre o produto disponibilizado e o esperado pelo mercado.

Em várias entrevistas observou-se que os diretores das empresas sempre frisaram que os incentivos financeiros e profissionais foram muito direcionados aos produtos. Já para a comercialização, a incubadora procurava fazer contatos com possíveis clientes e em alguns casos, viabilizava a exposição dos produtos ou projetos em feiras especializadas. Não há um trabalho de análise da aderência do produto ao mercado, seja ele na fase inicial ou intermediária do desenvolvimento. Segundo comentários de um diretor entrevistado: "Tenho através da incubadora várias horas de consultoria de produto, mas não me disponibilizam recursos para pesquisa mercadológica".

A análise acima pode ser corroborada com alguns exemplos de empresas que concluíram seus protótipos, mas não conseguiram comercializar nenhuma unidade. Muitas empresas também criaram outros produtos/serviços durante 0 período de incubação para atender as necessidades específicas de clientes e gerar renda. Essa mudança de foco atrapalha o desenvolvimento do produto inicial, conforme a seguinte afirmação: "Não tínhamos fonte de renda e aí resolvemos prestar serviços de T.I. - fazer sistemas para web - para ganharmos dinheiro no curto prazo e financiar o nosso projeto. Acontece que não conseguimos levar os dois trabalhos e o projeto principal ficou parado!" (entrevista - Diretor de uma empresa incubada).

Percebe-se claramente uma preocupação exacerbada com a concepção do produto em detrimento a outros importantes fatores, tais como: análise ambiental externa, análise mercadológica e comportamento do consumidor. Conforme a teoria, 
a estruturação da empresa excede simplesmente a criação de um produto e compreende um planejamento completo que inclui a criação do produto, a alocação eficiente dos recursos e também a sua comercialização.

De maneira similar, trabalhando a questão da estratégia e da vantagem competitiva sustentável em vinícolas argentinas do Vale do Rio Negro, Fernández (2008) constata que as empresas de alto desempenho valorizam mais os recursos relacionados aos aspectos comerciais e de mercado em detrimento dos aspectos de produção e de acesso a capital e insumos. Assim, a importância de se trabalhar os elos mais à jusante da cadeia como, por exemplo, os representantes comerciais e lojistas.

Diante destas deficiências apontadas pelas empresas incubadas, partiu-se para a análise em empresas graduadas. O número levantado foi de apenas $39 \%$ das empresas que se graduaram continuam no mercado comercializando seus produtos desenvolvidos na incubadora ou mesmo outros desenvolvidos após a graduação. Para sobreviver no mercado muitas também passaram a prestar serviços diversos. Outra fatia, 37\% foram incorporadas por outras ou mesmo fecharam suas portas devido a dificuldades encontradas no mercado. Por fim, o restante que corresponde a $24 \%$ das empresas graduadas, retornou para a incubadora atrás de incentivos e investimentos.

Analisando-se os números acima, percebe-se que a taxa de sucesso apresenta-se baixa diante dos vultosos investimentos governamentais e privados nas incubadoras. Uma fatia considerável das empresas não suporta a independência, tendo que voltar a fase de incubação para poder sobreviver, ou no pior dos casos, fechar as portas.

As empresas graduadas estudadas apontaram que sofreram as mesmas deficiências mercadológicas sofridas hoje pelas empresas incubadas. Muitas tiveram que adaptar os produtos originais ou mesmo desenvolver outras linhas de produtos para sobreviver. Segundo o depoimento de alguns entrevistados, muitos investimentos foram alocados para a concepção do produto ou do serviço, e pouco 
ou insuficiente recurso foi destinado para a estruturação comercial do negócio. Pode-se notar, desta forma que pouco se pensou na sustentabilidade do negócio.

Percebe-se assim uma grave deficiência apontada pelas empresas incubadas e graduadas referente à alocação dos recursos destinados elas mesmas. Vê-se ainda, uma preocupação muito grande em relação à concepção do produto e uma acentuada falta de preocupação em relação ao alinhamento mercadológico dos produtos/serviços gerados. Fato este verificado tanto em relação às empresas que estão incubadas como aquelas que já se graduaram e estão no mercado.

Isto remete a algumas reflexões sobre a correta alocação dos recursos públicos, muitas vezes concedidos a fundos perdidos, o papel empreendedor das incubadoras e o preparo para a independência das empresas que ali se encontram.

\section{Política de Admissão das Incubadoras}

Entre as incubadoras pesquisadas, todas apresentam vagas (disponibilidade) em suas estruturas. Ao contrário do que muitos imaginam, a ociosidade ainda é grande entre as incubadoras pesquisadas. Este fato preocupa alguns gestores de incubadoras que buscam fomentar a ocupação da estrutura disponível e em alguns casos, deixam de considerar certos aspectos técnicos.

Nas entrevistas, alguns gestores declararam que para a admissão bastava o projeto se encaixar com o perfil da incubadora e fosse apresentado um plano de negócios. Isto se mostrou diferente em uma das incubadoras pesquisadas e por isto, apresentou as melhores taxas de sucesso em graduação de empresas. Para admissão nesta incubadora, além dos aspectos legais como adequação do produto ao objetivo da incubadora, apresentação do plano de negócios e entrega de documentos, a análise passa por três analistas, sendo um técnico que estuda a viabilidade técnica da fabricação do produto, outro técnico em mercado que faz a análise mercadologia do futuro produto e por fim, um técnico próprio da incubadora que faz a análise final do plano de negócios. 
Esta análise mercadológica realizada por um especialista no setor pretendido torna-se importante no processo inicial, pois pode alertar tanto a incubadora como o futuro incubado sobre os aspectos mercadológicos frágeis no plano de negócios, ou mesmo rejeitar o futuro empreendimento face a possível não comercialização do produto desenhado. Percebe-se claramente que esta incubadora, por ter um processo de admissão alinhado com o mercado, apresenta as melhores taxas de sucesso do que as outras pesquisadas.

A política de admissão nas incubadoras pesquisadas reflete a falta de foco com os aspectos mercadológicos dos produtos que serão desenvolvidos. A falta destas políticas pode ser analisada em relação aos gestores das incubadoras onde, em sua maioria, são professores das universidades filiadas. Parece haver uma carência de experiências mercadológicas por parte destes docentes universitários. Notou-se também em uma das incubadoras, a preocupação em preparar o gestor para analisar os projetos enviados, visto que a taxa de sucesso torna a incubadora mais conhecida e melhor vista no mercado.

A reflexão neste ponto repousa na necessidade das incubadoras em criar e aplicar eficazmente, instrumentos de admissão e seleção dos pretendentes à incubação. A correta construção destes instrumentos pode possibilitar o incremento da taxa de sucesso dos projetos e atingir o objetivo de preparar as empresas para o mercado.

\section{Comprometimento das Empresas}

$\mathrm{Na}$ visão dos empresários incubados, as incubadoras ainda são vistas como entidades que pode desenvolver produtos a custos baixos e, principalmente, ser fontes de recursos. Estes recursos, na sua maioria, são provenientes de projetos governamentais para fomento de novas empresas e auxílio às incubadoras. Os recursos destinados a estes projetos são, em grande parte, a fundo perdido. Ou seja, as empresas que recebem estes recursos não precisam prestar contas futuras. 
Este tipo de fundo é o mais comum e está presente em praticamente todos os projetos.

Os recursos chegam para as empresas através de consultorias especializadas, auxílio no registro de produtos e solicitação de patentes, subsídio para criação de material promocional e também para participação em feiras e congressos, dentre outras formas.

Vários empresários entrevistados listaram os diversos serviços prestados pelas incubadoras e, em sua maioria, focaram aspectos produtivos e alguns poucos esforços comerciais. Ainda abrangem aspectos administrativos referentes à gestão das empresas incubadas.

Apesar de as empresas que são incubadas firmarem um acordo com as incubadoras, é constatado que muitas já graduadas não mantêm vínculo com as incubadoras, nem cumprem as cláusulas contratuais de destinarem uma parte dos lucros por dois anos às suas incubadoras de origem. Isto acaba enfraquecendo as incubadoras que dependem exclusivamente de recursos governamentais para sua sustentação.

O fato acima relatado descreve a falta de comprometimento entre a empresa e a incubadora. Da mesma forma, este grau de comprometimento é refletido no uso dos recursos. Muitas empresas investem os recursos recebidos sem nenhuma política alinhada com a estratégia e o mercado.

Por tais razões, emergem algumas reflexões sobre a eficiência da aplicação dos recursos governamentais nas incubadoras, bem como avaliar se os recursos empregados estão sendo utilizados de forma eficiente pelas empresas e pelas incubadoras.

\section{Considerações Finais e Contribuições}

O empreendedorismo é um campo de estudo em desenvolvimento com uma riqueza que contempla vários tipos de estudo e aplicações. Como tema adjacente, mas não secundário do empreendedorismo, estão as incubadoras. Tendo como ABIB, G. et al; O papel construtivo das incubadoras no alinhamento estratégico e mercadológico das empresas incubadas e graduadas. Revista de Empreendedorismo e 
metáfora as incubadoras neonatais, as tecnológicas procuram proteger, desenvolver e fomentar a criação e sustentação de novas empresas.

Utilizando a Visão Baseada em Recursos (VBR), o campo estratégico procura focar nos recursos e competências da empresa, ao invés do setor industrial, como fator principal de lucratividade e sucesso da empresa. A VBR ganha destaque em ambientes dinâmicos, onde o modelo Porteriano tem dificuldades de análise e aplicação. Ademais, recursos e competências podem ser conceituados como sendo os elementos pertencentes à organização e que permitem a ela a realização de suas atividades operacionais e estratégicas.

Um conceito importante dentro da literatura de estratégia é o de alinhamento estratégico. As empresas precisam estar alinhadas com o mercado para que possam continuar sustentando ou adquirindo vantagem competitiva sobre as outras concorrentes. Aquelas empresas que estão "desalinhadas" tendem a ter retorno inferior e, consequentemente, estão mais fadadas ao fracasso e a extinção (ZACCARELLI, 2000).

Como resultado, observa-se em todas as incubadoras pesquisadas que 0 foco dado às empresas incubadas está centrado estritamente na concepção do produto. Nesta fase, as empresas recebem muitos investimentos e as incubadoras por serem de base tecnológica acentuam este viés. Este fato leva a uma realidade constatada nas empresas graduadas: faltam esforços para entender e manter a sua adaptação de mercado.

Muitas empresas desenvolveram produtos inovadores, interessantes, mas sem sucesso no mercado. Isto retrata uma grande falha das incubadoras que negligenciam, na maioria das vezes, o alinhamento das incubadas com o mercado. O que também contribui para este fato são as deficiências das políticas de admissão, onde o projeto a ser incubado passa por uma fase de análise de mercado por especialistas que podem analisar se os produtos propostos poderão ter sucesso ou não no mercado. Muitas empresas que se graduaram tiveram que voltar tempos depois para a incubação, pois não se mostraram aptas a sobreviverem sozinhas no mercado.

ABIB, G. et al; O papel construtivo das incubadoras no alinhamento estratégico e mercadológico das empresas incubadas e graduadas. Revista de Empreendedorismo e 
Os recursos investidos nas empresas incubadas são, em sua maioria, a fundo perdido, o que acaba não gerando comprometimento em relação aos recursos recebidos. Somado a isso, as empresas depois que se graduam não costumam contribuir para o sustento das incubadoras, apesar das cláusulas contratuais. Ademais, verifica-se que faltam instrumentos de mensuração para as incubadoras e seus gestores para detectar estes problemas e medir a eficiência dos recursos recebidos e aplicados. Sugere-se uma mudança na política de concessão e cobrança dos recursos oferecidos pelo governo, buscando a efetividade da sua aplicação.

Outro resultado repousa na análise e adequação das políticas de admissão das incubadoras, e ainda um posterior acompanhamento dos resultados obtidos por estas incubadoras. Este fato afeta diretamente as taxas de sucesso das empresas incubadas e graduadas e auxilia na eficiência das políticas governamentais de fomento.

Nesta seara, vasto é o campo de pesquisas, uma vez que as incubadoras podem ser estudadas sob diferentes perspectivas. Como sugestões de pesquisas futuras, os autores sugerem que a teoria Institucional pode enriquecer o tema das incubadoras, bem como a Visão das Competências Dinâmicas que possibilita verificar o compartilhamento de recursos e competências dentro destas redes. Quando se fala em recursos podem ser estudados os atores (formação $x$ taxa de sucesso); inovação (relações entre a empresa e as universidades) e ainda relacionar tipos de produtos com a taxa de graduação das empresas.

Por derradeiro, cumpre dizer que a extensão do estudo para outros tipos de incubadoras também pode enriquecer ainda mais o campo e permitir estudos comparativos no âmbito do alinhamento estratégico mercadológico.

\section{Referências}

Associação Nacional de Entidades Promotoras de Empreendimentos Inovadores. 2006. 
$<$ http://www.anprotec.org.br/ArquivosDin/Graficos Evolucao 2006 Locus pdf 59.pd f >. Acesso em: em 1 jul. 2011.

Associação Nacional de Entidades Promotoras de Empreendimentos Inovadores. 2009. <http://www.anprotec.org.br/publicacao.php?idpublicacao=117> . Aceso em: 1.jul. 2011.

ANSOFF, I. H.. Corporate strategy. New York: McGraw-Hill, 1965.

ANSOFF, I. H.; MCDONNELL, E. J. Implantando a administração estratégica. São Paulo: Atlas, 1993.

BARDIN, L. Análise de conteúdo. Lisboa: Setenta, 1994.

BARNEY, J. Gaining and sustaining competitive advantage. Reading, MA: Adisson Wesley, 1997.

BARNEY, J.; HESTERLY, W. Organizational economics: understanding the relationship between organizations and economic analysis. In: CLEGG, S. R.; HARDY C.; NORD W. R. (Eds.), Handbook of organization studies. London: Sage Publications, 1996. p. 115-147.

BOAVA, D. L. T.; MACEDO, F. M. F. Empreendedorismo explicitado à maneira dos filósofos. In: ENCONTRO DE ESTUDOS EM ESTRATÉGIA, 5., 2011, Porto Alegre. Anais...Rio de Janeiro: Anpad, 2011.

BOAVA, D. L. T.; MACEDO, F. M. F.; LOPES, P. C. Percepções de empresários incubados em face do contexto empreendedor. In: ENCONTRO NACIONAL DA ASSOCIAÇÃO NACIONAL DE PÓS-GRADUAÇÃO E PESQUISA EM ADMINISTRAÇÃO, 30., set. 2006, Salvador. Anais... Rio de Janeiro: Anpad, 2006.

BOWMAN, C.; AMBROSINI, V. Value creation versus value capture: towards a coherent definition of value in strategy. British Journal of Management, v. 11, n.1, p. 1-15, 2000.

CALBINO, D. A educação e a gestão na economia solidária: um estudo dos processos de formação das incubadoras tecnológicas de cooperativas populares. Dissertação (Mestrado em Administração) - Universidade Federal de Minas Gerais, Belo Horizonte, MG, Brasil, 2010.

CALBINO, D.; PAULA, A. P. Embates sobre a neutralidade da gestão e a ressignificação do conhecimento gerencial nas incubadoras tecnológicas de cooperativas populares. In: ENCONTRO NACIONAL DE ESTUDOS ORGANIZACIONAIS, 6., 2010, Florianópolis. Anais... Rio de Janeiro: Anpad, 2010

ABIB, G. et al; O papel construtivo das incubadoras no alinhamento estratégico e mercadológico das empresas incubadas e graduadas. Revista de Empreendedorismo e Gestão de Pequenas Empresas, v.1, n.2, 2012. 
COHEN, M.; LOUZADA, B. H.; LUCENA, C. A. P.; MELO, L. J. Avaliação das atitudes e comportamentos de empreendedores de uma incubadora sobre a dimensão ambiental da sustentabilidade. In: ENCONTRO DA ASSOCIAÇÃO NACIONAL DE PÓS-GRADUAÇÃO E PESQUISA EM ADMINISTRAÇÃO, 33., 2009, São Paulo. Anais....Rio de Janeiro: Anpad, 2009.

CRESWELL, J. W. Research design: qualitative, quantitative and mixed methods approaches. 2. ed. Thousand Oaks: Sage Publications, 2003.

DAY, G. S. The capabilities of market-driven organizations. Journal of Marketing, v. 58, n.4, p. 37-52, 1994.

DOLABELA, F. O segredo de Luísa. Rio de Janeiro: Sextante, 2008.

DORNELAS, J. C. A. Empreendedorismo: transformando ideias em negócio. Rio de Janeiro: Campus, 2001.

DORNELAS, J. C. A. Empreendedorismo corporativo: conceitos e aplicações. Revista de Negócios, v. 9, n. 2, p. 81-90, 2004.

ENGELMAN, R.; FRACASSO, E. M. Contribuição das incubadoras tecnológicas na internacionalização das empresas incubadas. In: SIMPÓSIO DE GESTÃO DA INOVAÇÃO TEÇNOLÓGICA DA ASSOCIAÇÃO NACIONAL DE PÓS-GRADUAÇÃO E PESQUISA EM ADMINISTRAÇÃO, 26., 2010, Vitória. Anais... Vitória, 2010.

FERNÁNDEZ, S. P. O papel dos recursos estratégicos no desempenho competitivo internacional: casos de análises no setor vitivinícola do Vale do Rio Negro Argentino. Tese (Doutorado em Agronegócios) - Universidade Federal do Rio Grande do Sul, Porto Alegre, RS, 2008.

FERREIRA, J. M.; GIMENEZ, F. A. P.; RAMOS, S. C. Potencial empreendedor e liderança criativa: um estudo com varejistas de materiais de construção da cidade de Curitiba/Pr. In: ENCONTRO NACIONAL DA ASSOCIAÇÃO NACIONAL DE PÓSGRADUAÇÃO E PESQUISA EM ADMINISTRAÇÃO, 29., 2005, São Paulo. Anais... Rio de Janeiro: Anpad, 2005.

FILION, L. J. Entendendo os intraempreendedores como visionistas. Revista de Negócios,v. 9, n. 2, p. 65-80, 2004.

FREITAS, H. M. R.; JANISSEK, R. Análise léxica e análise de conteúdo: técnicas complementares, sequenciais e recorrentes para exploração de dados qualitativos. Porto Alegre: Sagra Luzzatto, 2000.

GALLON, A. V.; LYRIO, M. V.; ENSSLIN, S. R. Gerenciamento do capital intelectual de uma EBT incubada: a contribuição da metodologia multicritério de apoio à

ABIB, G. et al; O papel construtivo das incubadoras no alinhamento estratégico e mercadológico das empresas incubadas e graduadas. Revista de Empreendedorismo e Gestão de Pequenas Empresas, v.1, n.2, 2012. 
decisão construtivista. In: ENCONTRO NACIONAL DA ASSOCIAÇÃO NACIONAL DE PÓS-GRADUAÇÃO E PESQUISA EM ADMINISTRAÇÃO, 32., 2008, Rio de Janeiro. Anais... Rio de Janeiro: Anpad, 2008.

GALUNIC, D. C.; RODAN, S. Resource recombinations in the firm: knowledge structures and the potential for schumpeterian innovation. Strategic Management Journal, v.19, n. 12, p. 1193-1201, 1998.

GIMENEZ, F. A.; PELISSON, C.; KRÜGER, E. G.; HAYASHI JR. P. Estratégia competitiva de pequenas empresas varejistas. In: FELISONI, C. (ORG.). Varejo competitivo. São Paulo: Atlas, 1999. p 52-72.

GRANT, R. M. The resource-based theory of competitive advantage: implications for strategy formulation. California Management Review, v. 33, n.3, p. 114-135, 1998.

GLOBAL Entrepreunership Monitor. Empreendedorismo no Brasil. Curitiba: IBQP, (2010).

HISRICH, R. D. ; PETERS, M. P. Empreendedorismo. Porto Alegre: Bookman, 2009.

HOELTGEBAUM, M. Pedagogia empreendedora (Entrevista com Fernando Dolabela). Revista de Negócios, v.9, n.2, p. 127-130, 2004.

JENKINS, M.; AMBROSINI, V.; COLLIER, N. Strategy as multi-perspectives. In: JENKINS M.; AMBROSINI V. (Eds.). Advanced strategic management: a multiperspective approach. Basingstone, Hampshire: Palgrave, 2002.

KRAAIJENBRINK, J.; SPENDER, J. C.; GROEN, A. J. The resource-based view: a review and assessment of its critiques. Journal of Management, v. 36, n.1, p. 349$372,2010$.

LALKAKA R. Technology business incubators: critical determinants of success. In: THE NEW YORK ACADEMY OF SCIENCES, 798., 1996, New York. Annals... New York, 1996. p. 270-290.

LAVILLE, C.; DIONNE, J. (1999). Análise de conteúdo. In: LAVILLE, C.; DIONNE, J. (Eds.) A construção do saber: manual de metodologia da pesquisa em Ciências Humanas. p. 214-235. Porto Alegre: Artmed.

LEWIN A. Y.; VOLBERDA, H. W. The future of organization studies: beyond the selection-adaption debate. In: HITT, M. A.; FREEMAN R. E.; HARRISON J. S. (Eds.). The blackwell handbook of strategic management. Oxford: Blackwell Publisher, 2006. p. 568-595. 
LICHTENSTEIN, G. A.; LYONS, T. S. Incubating new enterprises: a guide to successful ractice. Washington: The Aspen Institute, 1996.

MARTINS, G. S.; LIMA. A. A. T. F. C.; SANTOS, C. A.; OlIVEIRA, A. R.; CARVALHO, R. M. M. A.; GOMES, R. C. Incubadoras de base tecnológica: um estudo sobre a capacitação gerencial no processo de incubação. In: ENCONTRO NACIONAL DA ASSOCIAÇÃO NACIONAL DE PÓS-GRADUAÇÃO E PESQUISA EM ADMINISTRAÇÃO, 29., 2005, Brasília. Anais... Brasília, DF.

MELO, L. J; COHEN, M. Empreendimentos inovadores, nova mentalidade? Um estudo exploratório sobre a sustentabilidade empresarial em uma incubadora de empresas. In: ENCONTRO DE ESTUDOS ORGANIZACIONAIS, 4., 2009, Recife. Anais... Rio de Janeiro: Anpad, 2009.

MILES, R. E.; SNOW, C. C. Organizational strategy, structure and process. New York: McGraw-Hil, 1978.

MINTZBERG, H.; AHLSTRAND, B.; LAMPEL, J. Safári da estratégia: um roteiro pela selva do planejamento estratégico. Porto Alegre: Bookman, 2000.

MONTGOMERY, C. A.; WERNERFELT, B. Sources of superior performance: market share versus industry effects in the U.S. brewing industry. Management Science, v. 37, n. 8, p. 954-959, 1991.

NUNES, M. P.; ANTUNES, J. A. JR. A promoção de inovações em novos empreendimentos através das relações da incubadora: um estudo de caso na incubadora RAIAR. In: ENCONTRO NACIONAL DA ASSOCIAÇÃO NACIONAL DE PÓS-GRADUAÇÃO E PESQUISA EM ADMINISTRAÇÃO, 34., 2010, Rio de Janeiro. Anais... Rio de Janeiro: Anpas, 2010.

OLIVEIRA, R.; OLIVEIRA, S.; PEREIRA, N. R. Análise das competências para inovar em incubadoras de empresas de base tecnológica. In: ENCONTRO NACIONAL DA ASSOCIAÇÃO NACIONAL DE PÓS-GRADUAÇÃO E PESQUISA EM ADMINISTRAÇÃO, 34., 2010, Rio de Janeiro. Anais... Rio de Janeiro: Anpad, 2010.

PORTER, M. Competitive strategy: techniques for analyzing industries and competitors. New York: The Free Press, 1980.

PRAHALAD, C. K.; RAMASWAMY, V. Co-opting customer competence. Harvard Business Review, v.78, n. 1, p.79-87, 2000.

PRAHALAD, C. K.; RAMASWAMY, V. The co-creation connection. Strategy + Business, v.27, n.2, p, 50-61, 2002. 
PRAHALAD, C. K.; RAMASWAMY, V. O futuro da competição: como desenvolver diferenciais inovadores em parcerias com os clientes. Rio de Janeiro: Elsevier, 2004.

PRIEM, R. L. A consumer perspective on value creation. Academy of Management Review, v. 32, n. 1, p. 219-235, 2007.

RAMOS, W.; ALPERSTEDT, G. D. O processo de internacionalização de uma empresa de software para moda: da incubadora ao investimento direto no exterior. In: ENCONTRO DE ESTUDOS EM ESTRATÉGIA, 5., 2011, Porto Alegre. Anais... Rio de Janeiro: Anpad, 2011.

RICHARDSON, R. J. Pesquisa social: métodos e técnicas. São Paulo: Atlas, 1999.

RICHERS, R. O que é o marketing. São Paulo: Brasiliense, 1981.

SANTOS, A. C. Z.; ALVES, M. S. Dimensões da orientação empreendedora e seus diferentes impactos no desempenho de empresas instaladas em incubadoras tecnológicas da região sul do Brasil. In: ENCONTRO NACIONAL DA ASSOCIAÇÃO NACIONAL DE PÓS-GRADUAÇÃO E PESQUISA EM ADMINISTRAÇÃO, 33., 2009, São Paulo. Anais...Rio de Janeiro: Anpad, 2009.

SCHULZE, W. S. (1994). The two schools of thought in resource-based theory: Definitions and implications for research. In: SHRIVASTAVA P.; HUFF A. S.; DUTTON J. E. (Eds.). Advances in strategic management: resource-based view of the firm. Greenwich: Jai Press, 1994, p. 127-152.

SILVA, M. A.; GOMES, L. F.; CORREIA, M. F. Cultura e orientação empreendedora: uma pesquisa comparativa entre empreendedores em incubadoras no Brasil e em Portugal. Revista de Administração Contemporânea, v.13, n.1, p.57-61, 2009.

SMILOR, R. W.; GIBSON, D. V.; DIETRICH, G. B. University spin-out companies: technology startups from UT-Austin. Journal of Business Venturing, v.5, n.1, p. 63$76,1990$.

SNOW, C. C.; MILES, R. E. The role of strategy in the development of a general theory of organizations. In: LAMB R. (Ed.). Advances in Strategic Management . Greenwich: Jay Press, 1993, p. 231-259.

VEDOVELLO, C.; FIGUEIREDO, P. N. Incubadora de inovação: que nova espécie é essa? RAE-eletrônica, v.4, n. 1, p. 1-18, 2005. Disponível em: $<$ http://www.scielo.br/pdf/raeel/v4n1/v4n1a06.pdf>

VOLBERTA, H. Building the flexible firm. Oxford: University Press, 1998. 
WERNERFELT, B. (1984). A resource-based view of the firm. Strategic Management Journal, v. 5, n. 2, p. 171-180, 1994.

WRIGHT, P.; KROLL, M.; PARNELL, L. Administração estratégica: conceitos. São Paulo: Atlas, 2000.

YIN , R . Estudo de caso: planejamento e métodos. 2 ed. Porto Alegre: Bookman, 2001.

ZACCARELLI, S. B. Estratégia e sucesso nas organizações. São Paulo: Saraiva, 2000.

Artigo recebido em 15/08/2012. Aprovado em 12/12/2012 